\title{
PERAN WATERFRONT CITY PADA INDUSTRI PARIWISATA TAMAN ALUN KAPUAS KOTA PONTIANAK
}

\author{
Dony Andrasmoro
}

Pendidikan Geografi IKIP PGRI Pontianak

( $\overline{\text { }}$ ) donny.andrasmara@gmail.com

\begin{abstract}
ABSTRAK
Peran Industri Pariwisata Indonesia mulai menjadi sorotan dunia akibat dampak dari peran pemerintah yang gencar mempromosikan branding "wonderfull Indonesia" di kancah dunia, sejalan dengan aspek itu penguatan potensi, daya tarik dan aspek pengembangan menjadi prioritas unggulan. Alternatif peran keseriusan industri pariwisata tercermin di setiap daerah, salah satunnya adalah Kota Pontianak. Kota Pontianak dengan destinasi wisata sungai menjadi prioritas dalam aspek pengembangan waterfront city taman Alun Kapuas. Tujuan penelitian ini adalah menelaah peran potensi taman Alun Kapuas sebagai destinasi pariwisata berbasis sungai (waterfront) di Kota Pontianak. Metode penelitian deskriptif perspektif menggunakan pendekatan kualitatif dengan beberapa pertanyaan terstruktur untuk mendapatkan informasi secara spesifik. Data penelitian ini diperoleh dari wawancara, observasi dan study literasi. Hasil penelitian ini menunjukkan bahwa penilaian terhadap Obyek wisata Taman Alun Kapuas menunjukkan wilayah pengembangan pariwisata Kota Pontianak meliputi obyek Taman Alun Kapuas dengan lokasi di kawasan pinggiran sungai Kapuas, dan berada berdekatan dengan pelabuhan Kota Pontianak sehingga memegang peran besar terhadap mobilitas dan daya tarik pariwisata di Kota Pontianak. Pengaruh potensi eksisting menjadikan daya tarik alami yang tidak semua obyek wisata di kota maupun daerah Kalimantan Barat memilikinya (unik) dan di upayakan menjadi sebuah ruang publik dengan pengembangan kajian model blue open public space berbasis pendekatan konsep penghijauan Sungai Kapuas (waterfront) yang bersifat rekreatif (recreational waterfront). Sejalan dengan konsep hal tersebut tercermin dari upaya pemerintah sesuai rencana pemerintahan Kota Pontianak pada RTRW 20132033 dan RPJMN 2015-2019 bahwa pengelolaan tata ruang Taman Alun Kapuas mencerminkan 4 strategi disain yaitu continuity, variety, connections dan sequence, sehingga dapat menciptakan destinasi wisata yang mewadahi kegiatan rekreatif berbasis waterfront city.
\end{abstract}

Kata kunci: Waterfront, Pariwisata, Sungai, Taman Alun.

\section{PENDAHULUAN}

"Waterfront City" menjadi salah satu solusi pengembangan destinasi pariwisata di Indonesia, mengingat bahwa indonesia memiliki kondisi geografis yang sangat kaya akan potensi alamnya. Secara fisiografis negara Indonesia adalah negara yang terletak pada koordinat $6^{\circ} \mathrm{LU}-11^{\circ} 08^{\prime} \mathrm{LS}$ dan dari $95^{\circ} \mathrm{BT}-141^{\circ} 45^{\prime} \mathrm{BT}$ serta terletak di antara dua benua yaitu benua Asia dan benua Australia/Oseania. Selain itu, Indonesia juga terletak pada pertemuan dua rangkaian pegunungan muda, yakni rangkaian Sirkum Pasifik dan rangkaian Sirkum Mediterania, sehingga banyak terdapat gunung dan pegunungan di Indonesia. Di Sisi kelautan, letak kelautan Indonesia sangat baik sebab wilayahnya yang berbentuk kepulauan dikelilingi oleh tiga lautan besar, yakni: bagian timur Indonesia berhadapan dengan Samudera Pasifik, bagian selatan Indonesia berhadapan dengan Samudera Hindia, dan bagian utara Indonesia berhadapan dengan Laut Cina Selatan, dari kondisi fisiografis tersebut menjelaskan bahwa Indonesia di dominasi oleh perairan baik laut, danau dan sungai yang berkarakteristik. Maka tidak heran ada kota-kota besar dengan pertumbuhan ekonomi, sosial budaya 
dan pariwisata di dukung oleh kawasan waterfront dengan konsep pengembangan waterfront city dan smart city diantarannya kota-kota besar tersebut adalah Makasar, Samarinda, Jayapura, Palembang, Surabaya, Semarang dan Pontianak.

Pengertian Waterfront City Development juga dapat diartikan suatu proses dari hasil pembangunan, yang memiliki kontak visual dan fisik dengan air dan bagian dari upaya pengembangan wilayah perkotaan, yang secara fisik alamnya berada dekat dengan air. Kota Pontianak merupakan kawasan dengan penataan ruang berbasis eco green and Living merupakan syarat mutlak bagi Pembangunan Kota, yang berwawasan Lingkungann sehingga dibangun dengan memperhatikan konsep Waterfront City bagi Perencanaan Pembangunan, yang berkelanjutan (Suistanable Project). (www.thecolourofindonesia.com).

Konsep pengembangan Kota Pontianak sesuai dengan master plan yang terintegrasi dengan konsep Sungai Kapuas dimana Sungai Kapuas termasuk Sungai terpanjang di Indonesia yaitu mencapai $1.143 \mathrm{~km}$ dan merupakan kawasan pengembangan ekonomi dan sosial budaya. Sesuai dengan Peraturan Pemerintah Daerah Kota Pontianak Nomor 2 Tahun 2013 Tentang Rencana Tata Ruang Wilayah Kota Pontianak Tahun 20132033 dalam Pasal 4 yang berbunyi:

"Mengembangkan kegiatan pariwisata, rekreasi dan perlindungan alam di kawasan pinggiran dan badan Sungai Kapuas dengan konsep waterfront city dan menjadi salah satu daya tarik kota".

Atraksi pariwisata utama yang terdapat pada kawasan Taman Alun Kapuas lebih terfokus pada aktivitas rekreasi di area taman dan waterfront dan merupakan ruang terbuka hijau gratis (umum). Keunikan yang dimiliki Taman Alun Kapuas yaitu sebuah taman langsung menghadap ke (dalam hal ini Sungai Kapuas) yang membentuk koridor sungai, dimana banyak kapal-kapal berukuran besar berlabuh di pelabuhan yang melewati Taman Alun Kapuas. Bagi masyarakat Kota Pontianak Taman Alun Kapuas dimanfaatkan untuk melepas waktu senggang sambil menikmati keindahan fasilitas waterfront diantarannya air mancur di depan Tugu Ekuator yang berada ditepian sungai, memancing ditepian sungai, ataupun aktivitas kelompok dengan beragam aktivitas dilakukan, mulai jalan-jalan santai, rekreasi keluarga, kuliner bagi wisatawan, serta pemanfaatan taman alunalun ini setiap tahun terdapat festival tahunan yaitu festival layang-layang, festival meriam karbit, cap go meh, pameran lukisan, hingga terdapat pasar murah. letak dan lokasinya juga sangat strategis karena berada dipusat kota dan open public space Kota Pontianak.

Andrasmoro (2015:151) menyatakan bahwa dalam pariwisata seringkali dipersepsikan sebagai mesin ekonomi penghasil devisa bagi pembangunan ekonomi di suatu negara, tidak terkecuali di Indonesia. Namun demikian, pada prinsipnya pariwisata memiliki spektrum fundamental pembangunan yang lebih luas bagi suatu negara. Pembangunan kepariwisataan pada dasarnya ditujukan untuk persatuan dan kesatuan bangsa, penghapusan kemiskinan (poverty alleviation), pembangunan berkesinambungan (sustainable development), pelestarian budaya (cultural preservation), pemenuhan kebutuhan hidup dan HAM, peningkatan ekonomi, dan industri, sekaligus pengembangan teknologi. Peran waterfront city pada industri pariwisata di Taman Alun Kapuas akan terdorong dengan baik dan meningkat apabila pariwisata sebagai "total tourism product" atau sebagai kata lain kombinasi dari semua element pelayanan yang di konsumsi wisatawan dari saat meninggalkan rumah sampai kembali lagi, sehingga agregat aktivitas produktif ditunjukkan untuk memenuhi kepuasan dan kebutuhan wisatawan (Richardson dan Fluker, 2004:50). Dengan mengembangkan pariwista sebagai suatu industri, perolehan devisa yang dibutuhkan untuk pembangunan ekonomi lebih cepat diperoleh dibandingkan dengan melakukan pengiriman komoditi keluar negeri (ekspor) yang memakan waktu relatif lama. Alternatif yeailding Industry memberikan dampak ke semua lini aset negara baik dari sisi invisible export yang berarti ekspor tidak nyata, karena memang tidak ada barang atau komoditi yang dikirim ke luar negeri. Devisa diperoleh dengan menarik wisatawan 
mancanegara datang berkunjung pada suatu negara. Daya dukung ini sangat tepat sekali di kembangkan dalam sektor pengembangan industry pariwisata berbasis waterfront city taman Alun Kapuas Kota Pontianak, karena berdasakan hasil World Travel \& Tourism Countil merekomendasikan agar pemerintah Indonesia secara nasional mempertimbangkan agar menetapkan industri pariwisata kota provinsi di Indonesia sebagai "prioritas strategis" bagi pengembangan ekonomi jangka panjang Indonesia di waktu-waktu akan datang.

\section{METODOLOGI PENELITIAN}

Penelitian ini adalah peran waterfront city pada industri pariwisata Taman Alun Kapuas Kota Pontianak, dengan sistem analisis persepsi dan teoritis. Analisis data dilakukan menggunakan metode deskriptif kualitatif persepsi. Analisis kualitatif adalah sebuah metode yang menggambarkan secara kualitatif fakta, data, obyek, material baik berupa, ungkapan bahasa atau wacana melalui interpretasi yang tepat dan sistematis (Wibowo, 2014). Peran waterfront city dianalisis secara deskriptif kualitatif perspektif dengan menginterpretasikan fakta yang ditemukan secara teoritis dan persepsi.

Data yang dikumpulkan terdiri dari data primer dan data sekunder. Data primer diperoleh langsung melalui studi lapangan, sedangkan data sekunder melalui studi literatur, kepustakaan dari sumber-sumber data atau informasi yang ada.

Data dikumpulkan dengan menggunakan teknik pengumpulan data gabungan berupa wawancara, diskusi, studi dokumentasi dan literatur. Analisis data secara deskriptif kualitatif perspektif dengan mentabulasikan data yang diperoleh sesuai dengan tujuan.

\section{HASIL dan PEMBAHASAN}

\section{Peran Waterfront City Taman Alun Kapuas}

Kota Pontianak merupakan kawasan Kota dengan konsep tataruangnnya berbasis sentralistik yaitu memiliki ketergantungan dengan Sungai Kapuas terutama dari kajian pariwisata, oleh karena itu masyarakatnya mencerminkan dengan keberadaan Taman Alun Kapuas menjadi bagian penting, masyarakat Kota Pontianak sering menghabiskan waktu libur bersama keluarga. Dari pagi, taman sudah dibuka dan biasanya pengunjung banyak melakukan olah raga seperti jogging, lalu menjelang sore taman sudah mulai banyak dikunjungi muda-mudi dan keluarga hingga larut malam.

Taman Alun Kapuas merupakan salah satu lokasi wisata di kota Pontianak Provinsi Kalimantan Barat. Tata letaknya di tengah kota menjadikan Taman Alun Kapuas bisa dikunjungi dari arah mana saja, maka wajar saja jika hampir setiap harinya lokasi ini ramai dikunjungi oleh masyarakat yang datang bersama keluarga dan tampak wisatawan asing datang ke tempat ini.

Taman yang merupakan salah satu proyek Waterfront City dari Pemerintah Kota Pontianak, dan sering disebut dengan nama Taman Alun Kapuas, terletak di pinggiran Sungai Kapuas, Pontianak, tepatnya berada di depan kantor Walikota Pontianak yakni di sekitaran Jalan Rahadi Usman. Dari tempat ini dapat dilihat pertemuan Sungai Kapuas dan Sungai Landak, kapal ferry dan sampan yang merupakan alat angkutan yang menjembati pusat kota dengan pinggiran kawasan Siantan dan Kampung Beting. Secara administrasi dapat dilihat dari gambar 1 peta administrasi.

\section{Perkembangan Industri Pariwisata Berbasis waterfront City di Kota Pontianak.}

a. Kondisi Industri Pariwisata Kota Pontianak

Industri pariwisata Indonesia untuk meningkatkan kontribusinya pada Produk Domestik Bruto (PDB) karena hal ini akan memicu lebih banyak pendapatan devisa (karena setiap turis asing menghabiskan rata-rata antara 1.100 dollar AS sampai 1.200 dollar AS per kunjungan) dan juga menyediakan kesempatan kerja untuk masyarakat Indonesia (berdasarkan data terakhir dari Badan Pusat Statistik, tingkat pengangguran di negara ini mencapai $5,81 \%$ di Februari 2015). Diperkirakan bahwa hampir 9\% dari total angkatan kerja nasional dipekerjakan di sektor pariwisata. Sejalan dengan tingkat perkembangannya sektor industri pariwisata 
memang menjanjikan terhadap pendapatan devisa negara.

Tercermin dari peran industri pariwisata di Indonesia Pemkot Kota Pontianak berbenah dalam meningkatkan tingkat kunjungan wisatawan baik domestik maupun internasional. Aspek ini tercermin dengan louncingnnya branding pariwisata Kota pontianak yaitu pada bulan Februari Tahun 2017 telah di resmikan city branding pariwisata yaitu "Pontianak Kota Khatulistiwa" dengan ikon resminya adalah Tugu
Khatulistiwa dengan tujuan supaya Kota Pontianak memiliki branding tersendiri dengan ciri khasnya. Untuk menyeimbangkan slogan Kota Pontianak "Menyapa Dunia", Pontianak sudah semestinya memiliki wajah tersendiri dengan mengusung city branding," Pariwisata seperti Kota Besar lainnya di Indonesia (Kompas 2017). Pemkot sudah mulai serius dan gencar mempromosikan pariwisata, aspek ini tercermin dari tingkat kunjungan wisatawan yang selalu meningkat dari tahun ke tahun. Grafik jumlah kunjungan wisatawan Kota Pontianak dapat dilihat pada gambar 2.

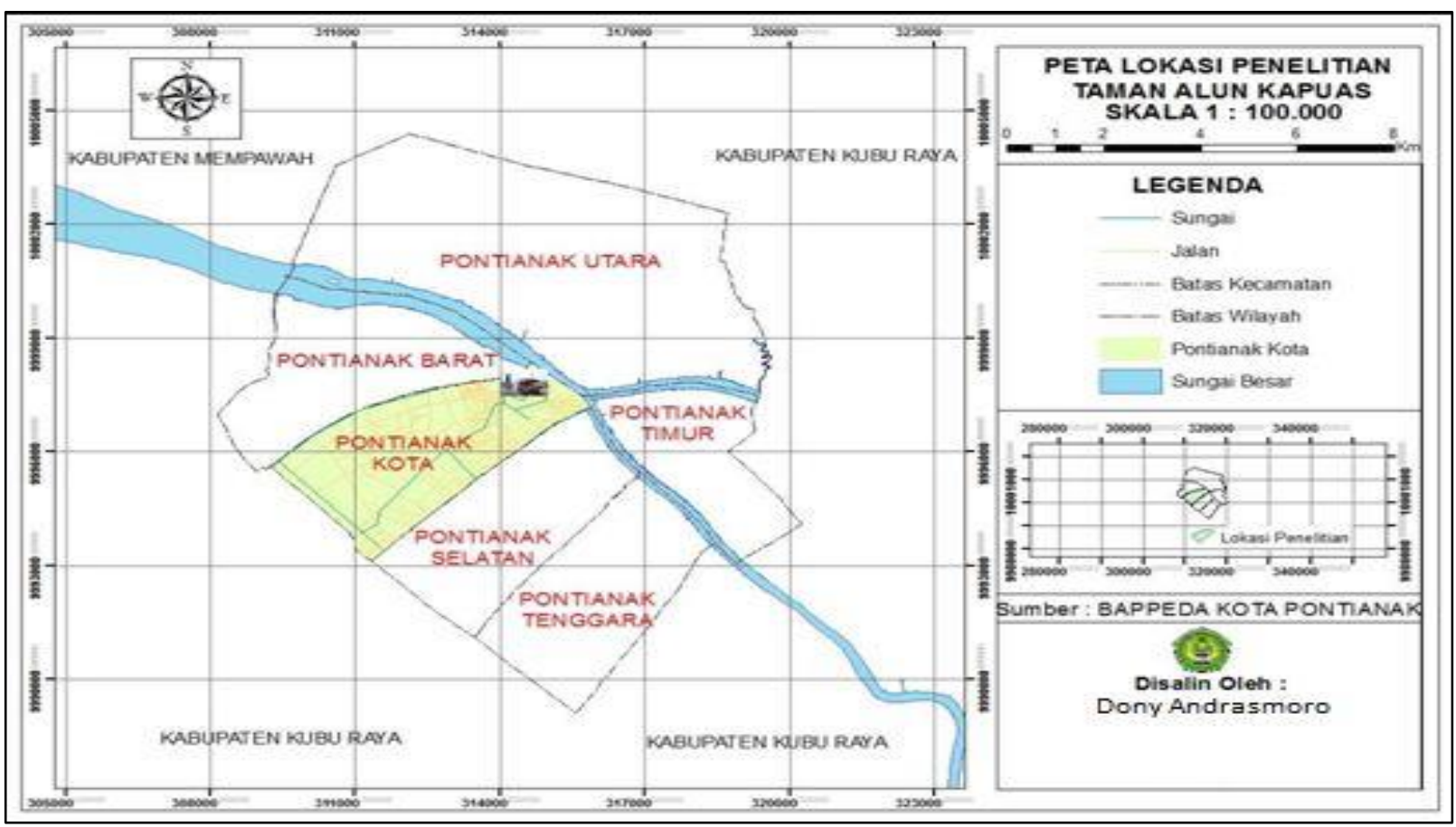

Gambar 1. Peta Administrasi Taman Alun Kapuas.

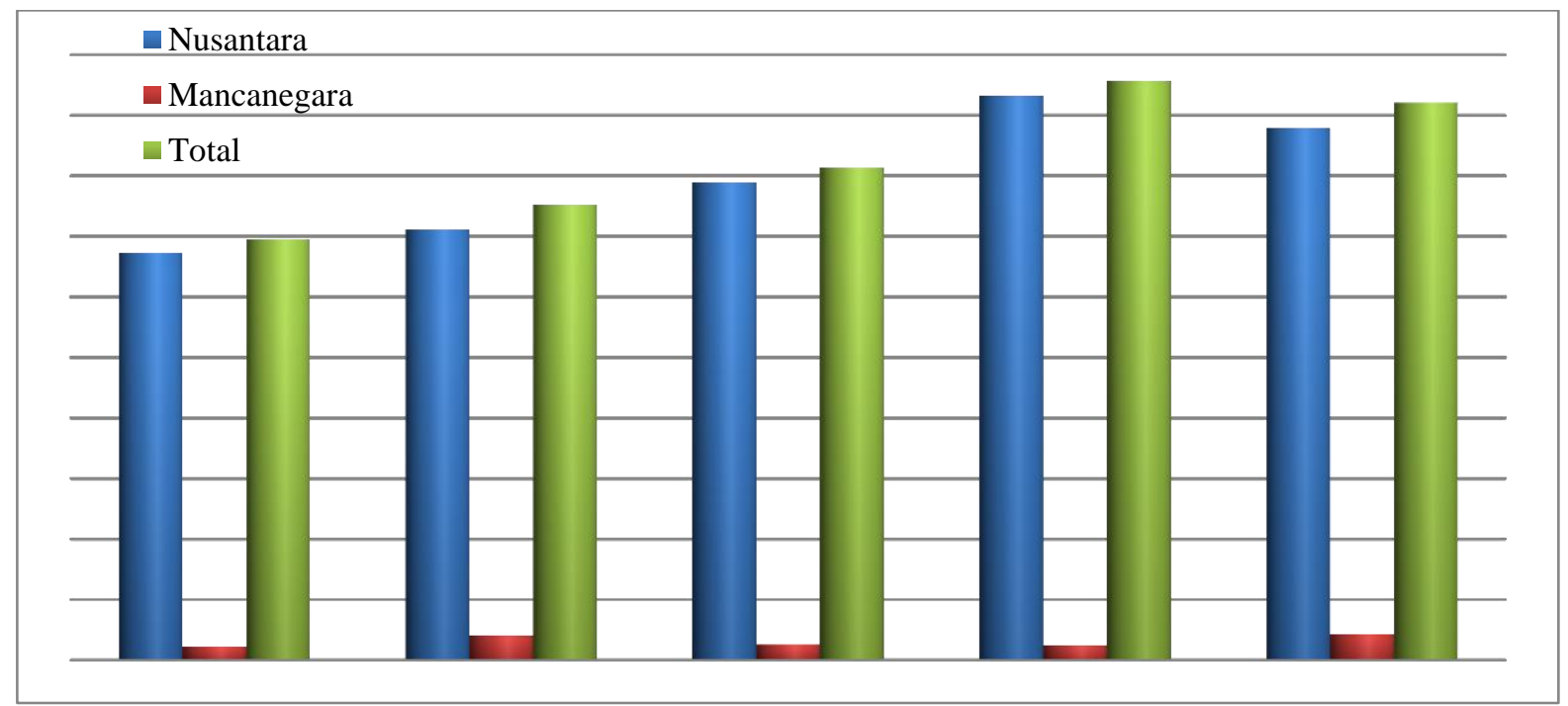

Gambar 2. Grafik Jumlah Kunjungan Wisatawan Kota Pontianak Tahun 2011-2015 (Dinas Kebudayaan dan Pariwisata Kota Pontianak, 2018). 
Berdasarkan gambar grafik di atas jumlah kunjungan wisatawan nusantara yang terbanyak mengunjungi Kota Pontianak ditemukan pada Tahun 2014 yaitu 932.070 wisatawan nusantara, sedangkan jumlah kunjungan wisatawan mancanegara terbanyak yaitu Tahun 2015 dengan jumlah 42.460 wisatawan dan jumlah total wisatawan nusantara dan mancanegara terbanyak pada Tahun 2014 yaitu 957.025 wisatawan yang berkunjung ke Kota Pontianak.

b. Peran Perkembangan Industri Pariwisata Waterfront City Taman Alun Kapuas.

Indikator konsep dalam peningkatan kualitas dan peran perkembangan industri Taman Alun Kapuas sebagai daya tarik wisata berbasis Waterfront City adalah identifikasi potensi obyek wisata taman rekreasi Alun Kapuas Kota Pontianak dengan penilaian pendekatan berdasarkan Yoeti (2012) dengan konsep 3A: (Atraksi, Aksesbilitas, dan Amenitas). Berikut defenisi hasil kajian potensi terhadap peran pengembangan industri pariwisata waterfront City Taman Laun Kapuas.

Tabel 1. Identifikasi Potensi Taman Alun Kapuas

\begin{tabular}{lll}
\hline No & $\begin{array}{l}\text { Kajian } \\
\text { Obyek } \\
\text { Wisata }\end{array}$ & Potensi \\
\hline 1. & Atraksi & $\begin{array}{l}\text { Taman Alun Kapuas, taman } \\
\text { air mancur }\end{array}$ \\
\cline { 3 - 3 } & & Ruang Terbuka Hijau (RTH) \\
\cline { 3 - 3 } & & $\begin{array}{l}\text { Dermaga Duplikat Tugu } \\
\text { Khatulistiwa }\end{array}$ \\
\cline { 3 - 3 } & & Perahu wisata, Kano \\
\hline 2. & Aksesibilitas & $\begin{array}{l}\text { Restoran Perahu, hotel, } \\
\text { kuliner perahu. }\end{array}$ \\
\hline 3. & Amanitas & $\begin{array}{l}\text { Parkir, toilet, } \\
\text { sampah, gazebo, open stage, } \\
\end{array}$ \\
& & $\begin{array}{l}\text { perpustakaan, arena bermain } \\
\text { anak }\end{array}$ \\
\hline
\end{tabular}

Sumber: Hasil Survei Peneliti, 2018

Secara geografis potensi fisik menjadi bagian dari sumber strategi pengembangan pariwisata. Keberadaan obyek wisata terbuka perlu adannya penilaian dan peninjauan terhadap hasil kajian, guna memperoleh data terhadap arah potensi dan aspek kajian pengembangan secara berkala. Tidak lepas dari aspek penilaian potensi secara fisik tetapi sentuhan nilai kreativitas juga sangat di butuhkan baik itu datang dari Pemkot sendiri maupun stakeholders dan komunitas muda kota pontianak. Berikut aspek kendala potensi dinilai dari kondisi geografis:

Tabel 2. Potensi Kawasan Wisata Objek Wisata Alur Sungai Kapuas

\begin{tabular}{|c|c|c|c|}
\hline No & $\begin{array}{l}\text { Kajian } \\
\text { Obyek } \\
\text { Wisata }\end{array}$ & Potensi & Kendala \\
\hline 1. & $\begin{array}{l}\text { Fisik dan } \\
\text { Topografi }\end{array}$ & 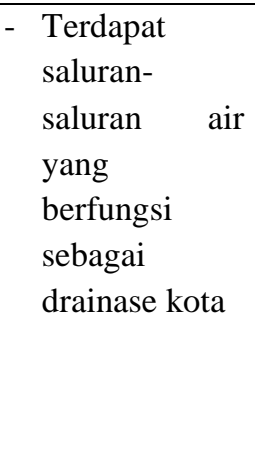 & 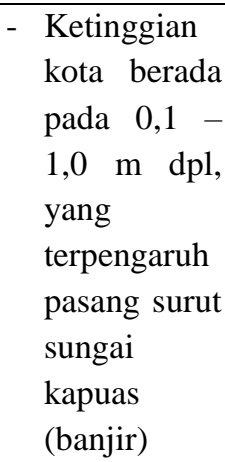 \\
\hline 2. & Iklim & - & - \\
\hline 3. & $\begin{array}{l}\text { Pengguna- } \\
\text { an Lahan }\end{array}$ & $\begin{array}{l}\text { Antara Alun } \\
\text { Kapuas sampai } \\
\text { Pelabuhan Seng } \\
\text { hie: } \\
\text { - Berupa } \\
\text { lahan } \\
\text { perkotaan } \\
\text { - Terdiri atas } \\
\text { bangunan } \\
\text { komersial, } \\
\text { hotel, } \\
\text { perkantoran, } \\
\text { perdagangan } \\
\text { dan } \\
\text { permukiman. }\end{array}$ & $\begin{array}{l}\text { Antara Alun } \\
\text { Kapuas s/d } \\
\text { Pel. Seng hie. } \\
\text { - Kepadatan } \\
\text { bangunan } \\
\text { relative } \\
\text { tinggi } \\
\text { - Bercampurn } \\
\text { ya fungsi } \\
\text { kegiatan } \\
\text { - Permukima } \\
\text { n dan } \\
\text { kawasan } \\
\text { perdaganga } \\
\text { n kumuh }\end{array}$ \\
\hline 4. & $\begin{array}{l}\text { Fasilitas } \\
\text { fungsi } \\
\text { kawasan }\end{array}$ & $\begin{array}{l}\text { Telah terdapat: } \\
\text { - Sarana umum } \\
\text { (air bersih, } \\
\text { listrik, telp, } \\
\text { warnet, } \\
\text { terminal, } \\
\text { pelabuhan, } \\
\text { dermaga, } \\
\text { pompa bensin } \\
\text { (SPBU), } \\
\text { angkutan } \\
\text { umum) } \\
\text { - Sarana sosial } \\
\text { (RS, } \\
\text { Puskesmas, }\end{array}$ & $\begin{array}{l}\text { - } \text { Sering } \\
\text { terjadi } \\
\text { pemadaman } \\
\text { listrik } \\
\text { - Pelayanan } \\
\text { dan rute } \\
\text { angkutan } \\
\text { umum } \\
\text { masih } \\
\text { terbatas } \\
\text { - Pelabuhan } \\
\text { kapal tidak } \\
\text { terawat }\end{array}$ \\
\hline
\end{tabular}




\begin{tabular}{|c|c|c|}
\hline No & $\begin{array}{c}\text { Kajian } \\
\text { Obyek } \\
\text { Wisata }\end{array}$ & Kendala \\
\hline & & $\begin{array}{l}\text { PT, Sekolah, } \\
\text { Tempat } \\
\text { Ibadah) } \\
\text { - Sarana } \\
\text { ekonomi } \\
\text { (Pasar, } \\
\text { pertokoan, } \\
\text { bank koperasi, } \\
\text { pasar) } \\
\text { - Sarana } \\
\text { Pemerintahan } \\
\text { (Kantor } \\
\text { Gubernur, } \\
\text { Walikota, } \\
\text { Camat, Lurah, } \\
\text { dll). }\end{array}$ \\
\hline
\end{tabular}

Sumber: Hasil Survei Peneliti, 2018

Aspek di atas mencerminkan ada empat faktor kendala dalam proses penilaian potensi secara geografis yaitu Topografis, Penggunaan lahan, iklim dan fasilitas fungsi kawasan. Mempertimbangkan kondisi hasil kajian potensi yang ada, perencanaan perkembangan Waterfront kawasan Taman Alun Kapuas dapat dinilai dengan model blue open public space dan membuat penghijauan (green) karena peran kawasan Waterfront city pada Taman Alun Kapuas dan kawasan alur sungai Kapuas Kota Pontianak dapat dikelola berdasarkan fungsinya:

1) Mixed-used Waterfront adalah waterfront yang merupakan kombinasi dari perumahan, perkantoran, restoran, pasar, rumah sakit,atau tempat-tempat kebudayaan.

2) Recreational Waterfront adalah kawasan makro area perairan waterfront yang menyediakan sarana-sarana dan prasarana untuk kegiatan rekreasi bagi wisatawan domestik maupun mancanegara, seperti taman, arena bermain, tempat pemancingan, dan fasilitas untuk kapal pesiar.

3) Residential Waterfront (kawasan hunian) adalah perumahan, hotel atau apartemen, dan resort yang dibangun di pinggir perairan.

4) Working Waterfront adalah tempat penangkapan ikan komersial, reparasi kapal pesiar, industri berat, dan fungsi-fungsi pelabuhan.

Berdasarkan kondisi saat ini, hasil kajian potensi yang mencerminkan perkembangan Waterfront kawasan Taman Alun Kapuas dapat di kembangkan dengan peran terhadap kajian model blue open public space dan membuat konsep penghijauan, yang sejalan dengan daya dukung upaya pemerintah dalam penelaahan fungsi kawasan sesuai rencana pemerintahan Kota Pontianak pada RTRW 2013-2033 dan RPJMN 2015-2019 bahwa pengelolaan tata ruang Taman Alun Kapuas mendorong 4 strategi disain yaitu continuity, variety, connections dan sequence, sehingga dapat menciptakan destinasi wisata yang mewadahi kegiatan rekreatif berbasis waterfront city yang ramah terhadap perkembangan dan kesehatan lingkungan.

\section{SIMPULAN}

Tujuan dari peran perencanaan industri pariwisata berbasis waterfront city adalah untuk menyelaraskan antara alam area hijau (Taman Alun Kapuas) dengan area biru (Sungai Kapuas), menarik sedekat mungkin area hijau ke sungai (area biru), membuat peneduhan dan mengurangi refleksi panas dari sinar matahari (kenyamanan thermal alami) dan membuat eye catcher bagi pejalan kaki dalam radius good living. Perencanaan ini dilakukan karena kecenderungan dan semakin pesatnya perkembangan pembangunan di tepian sungai Kapuas. Pada tempo dulu sungai dimanfaatkan sebagai muka bangunan dan perkembangan sekarang sungai sebagai muka belakang bangunan, jalan raya menjadi orientasi utama muka bangunan (bukan sungai). Seharusnya, perkembangan yang diinginkan adalah sungai sebagai muka bangunan (waterfront). Dimana air merupakan bagian kehidupan (living water) dan terdapat empat makna didalamnya yaitu:

1. Makna ekologi: melalui air mampu menghidupkan nilai-nilai ekologis, jalur hijau \& taman kota tepian sungai, wetland sebagai filter alami, dan biodiversity. Solusi bagi permasalahan kota tentang abrasi, sedimentasi, banjir dan air bersih. 
2. Makna sosial: melalui air mampu menghidupkan nilai-nilai sosial kota, ruang keluarga tepian sungai, open public space tepian sungai, promenade tepian sungai, menjadi struktur utama jaringan kota. Solusi bagi permasalahan kota tentang ruang komunal open public space.

3. Makna ekonomi: melalui air mampu menghidupkan nilai-nilai ekonomi, jalur perdagangan, jalur transportasi wisata dan domestik. Solusi bagi permasalahan kota tentang membangkitkan perekonomian local.

4. Makna identity: melalui air mampu menghidupkan nilai-nilai identitas (sejarah kebudayaan), jalur sequence kesejarahan dan budaya, edukasi hasil kekayaan alam. Solusi bagi permasalahan kota tentang membangkitkan citra kawasan dan kota.

\section{DAFTAR PUSTAKA}

Andrasmoro, Dony. 2015. Alternatif Pengurangan Efek Global Warming Terhadap Aktivitas Industri
Pariwisata Internasional. 151: Jurnal Edukasi, vol.13 No.2. IKIP PGRI Pontianak.

Badan Pusat Statistik. (2016). Berita Resmi No.25/03/Th.XIX, 01 Maret 2016.Jakarta: BPS Pusat.

Yoeti, Oka. 2012. Dasar-dasar Pengertian Hospitality dan Pariwisata. Bandung. PT Alumni.

Peraturan Pemerintah Daerah No.2 Tahun 2013. Tentang Rencana Tata Ruang Wilayah Kota Pontianak Tahun 2013-2033. Kota Pontianak: BAPPEDA.

Richardson, John I dan Martin Fluker. 2004. Understending and Managing Tourism. Australia: Pearson Education Australia, NSW Australia.

Undang - undang Republik Indonesia Nomor 10 Tahun 2009. Tentang Kepariwisataan. Jakarta: DPR RI.

Wibowo, W. 2014. Cara Cerdas Menulis Artikel Ilmiah. Kompas. Jakarta. 